\title{
PERAN PENGELOLAAN ANGGARAN PEMERINTAH DALAM PEMUDARAN KESENJANGAN PENDIDIKAN DI INDONESIA
}

\author{
Rah Adi Fahmi Ginanjar ${ }^{1 *}$, Stannia Cahaya Suci², Cep Jandi Anwar³, \\ Vadilla Mutia Zahara ${ }^{4}$, Indra Suhendra ${ }^{5}$ \\ 1,2,3,4,5 Jurusan Ilmu Ekonomi Pembangunan, Universitas Sultan Ageng Tirtayasa, \\ Serang-Indonesia \\ *rah.adi@untirta.ac.id
}

\begin{abstract}
ABSTRAK
Penelitian ini bertujuan untuk menganalisis peran penerimaan dan belanja pemerintah daerah pada proses dispersi kesenjangan hasil pendidikan di Indonesia dengan pengamatan pada seluruh daerah selama satu dekade, 2010-2019. Hasil analisis dengan pendekatan konvergensi sigma ditemukan bahwa telah terjadi proses dispersi kesenjangan indeks pendidikan antar daerah. Kemudian hal ini dipertegas oleh hasil analisis dengan pendekatan konvergensi beta dengan menggunakan model System-GMM bahwa konvergensi telah terjadi namun akselerasinya relatif lambat. Hal ini merupakan konsekuensi dari peran pengelolaan anggaran pemerintah yang belum optimal karena dari sisi penerimaan pemerintah daerah yang diwakili oleh indikator dari dana perimbangan, ditemukan bahwa Dana Alokasi Khusus (DAK) dan Dana Alokasi Umum (DAU) telah memberikan pengaruh negatif secara signifikan terhadap konvergensi indeks pendidikan. Kemudian dari sisi belanjanya ditemukan bahwa Belanja Langsung sudah memberikan pengaruh positif secara signifikan terhadap konvergensinya, sedangkan Belanja Tidak Langsung tidak signifikan. Dengan demikian, temuan ini membuka peluang bagi indeks pendidikan untuk menjadi dimensi tersendiri dalam menentukan dana dana perimbangan guna percepatan konvergensi hasil pendidikan di Indonesia.
\end{abstract}

Kata kunci: kesenjangan regional, outcome pendidikan, desentralisasi fiskal, keuangan daerah, model GMM.

\begin{abstract}
This study aims to analyze the convergence process of educational outcomes in Indonesia and determine the role of government budget allocation in accelerating convergence by observing all regions from 2010-2019. According to the results of the $\sigma$-convergence analysis, it is found that the dispersion explains the convergence process of the educational index gap. Then confirmed by the results of conditional $\beta$-convergence analysis by the System-GMM model, it was found that the convergence speed was relatively slow. This is a consequence of the role of government budget management which has not been optimal. In terms of regional revenues, it is found that the specific purpose transfer and the general purpose transfer have a significant negative effect on the convergence of the education index. Then from the expenditure side, it is known that direct expenditure has a significant positive effect on convergence, while indirect expenditure is not significant. Thus, this evidence opens up opportunities for the educational index to become a separate dimension in determining purpose transfer to the regions to accelerate the convergence of educational outcomes.
\end{abstract}

Keywords: regional inequality, educational outcomes, fiscal decentralization, public finance, GMM estimation. 


\section{PENDAHULUAN}

Anggaran pendidikan senantiasa semakin meningkat dalam perkembangannya, namun isu kesenjangan pendidikan telah berlangsung cukup lama dan diperkirakan masih relevan untuk beberapa periode ke depan. Gambar 1 di bawah menunjukkan perkembangan alokasi anggaran pendidikan yang terus mengalami peningkatan signifikan mulai dari tahun 2010 yang hanya sebesar $10 \%$ dari APBN atau Rp 225,2 triliun hingga mencapai Rp 492,5 triliun atau 20\% dari APBN. Perkembangan ini seakan tidak bermakna karena disparitas pendidikan antardaerah masih terus terjadi sampai saat ini dan cukup signifikan apabila dilihat dari capaian Indeks Pendidikan (IP) Provinsi DI Yogyakarta dibandingkan dengan Provinsi Papua. Perbedaan capaian IP antara kedua provinsi tersebut cenderung semakin kecil dalam kurun waktu 2010 hingga 2019, namun kemajuannya cenderung lambat. Pada tahun 2010, IP Provinsi DI Yogyakarta tercatat sebesar 67,7 dan mencapai 74,5 pada tahun 2019, ini merupakan provinsi dengan nilai IP tertinggi di Indonesia. Sementara itu, capaian Provinsi Papua tercatat hanya dari 42,4 menjadi 52,9 pada tahun terakhir, dan merupakan yang terendah. Dengan demikian, jarak kesenjangan antar kedua provinsi tersebut pada tahun terakhir berselisih sebesar 21,7.

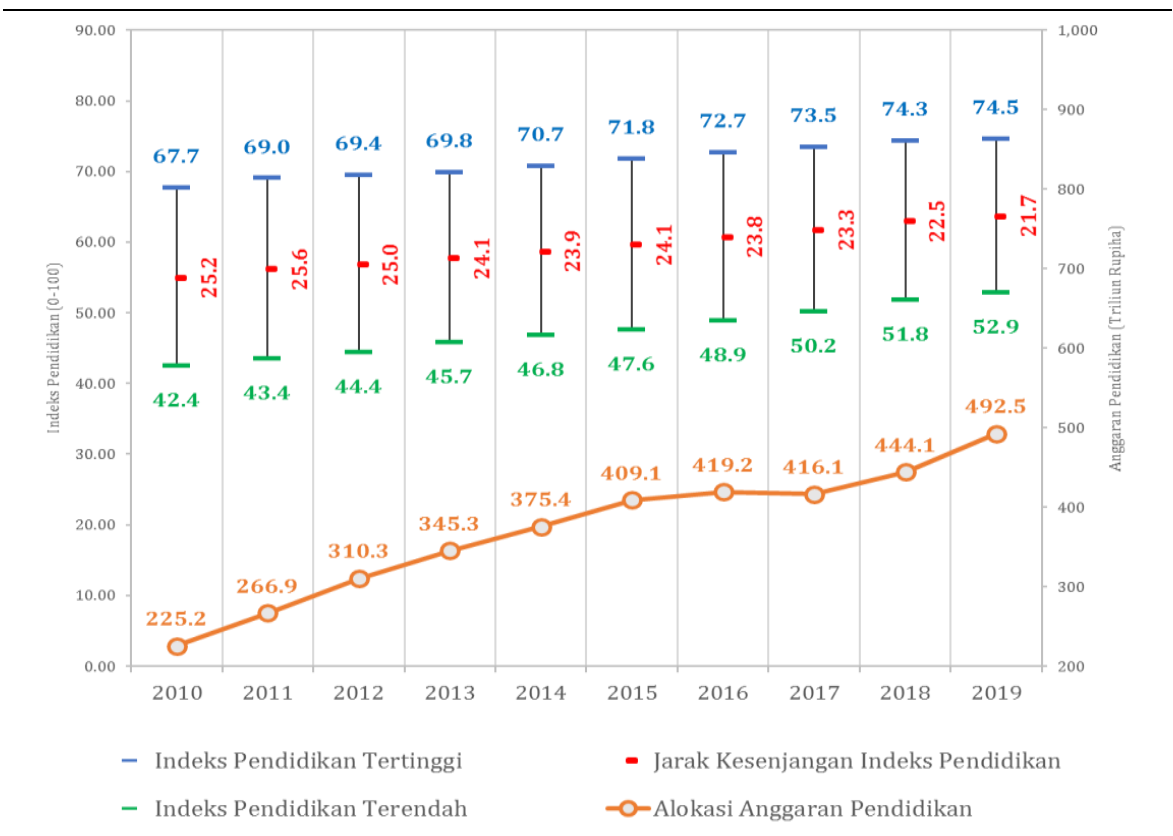

(Sumber: perhitungan penulis berdasarkan data BPS dan Kemenkeu-RI, 2020)

Gambar 1. Alokasi Anggaran Pendidikan dan Kesenjangan Indeks Pendidikan di Indonesia, 2010-2019

Penelitian terkait dengan pendidikan yang dikaitkan dengan keuangan daerah telah diuji pada berbagai penelitian. Hakim et al. (2020) meneliti seberapa jauh pemanfaatan DAU oleh pemerintah daerah. Kurniawati et al. (2018) merumuskan sebuah kerangka konseptual pengadaan infrastruktur pendidikan dasar dan menengah melalui KPBU dengan skema belanja ketersediaan layanan. Rifa’i 
\& Listiono (2018) menganalisis dampak kebijakan desentralisasi fiskal terhadap penyediaan fasilitas pendidikan. Sumardjoko (2017) menelaah peran earmarked grants pada pola belanja daerah dan bagaimana kontribusinya untuk mendorong pertumbuhan ekonomi regional. Triyanto \& Pamungkas (2017) mencari hubungan antara pengalihan kewenangan pendidikan menengah dan beban fiskal, bagaimana pengaruh pengalihan kewenangan tersebut pada kebijakan alokasi DAU, serta perbandingan kondisi ruang fiskal provinsi sebelum dan setelah adanya pengalihan kewenangan. Adapun beberapa penelitian yang meneliti hubungan antara keuangan daerah dengan IPM, dimana terdapat dimensi pendidikan di dalamnya, seperti yang dilakukan Sembiring (2019) mengindentifikasi Pengaruh Pendapatan Asli Daerah, Dana Alokasi Umum, dan Dana Alokasi Khusus terhadap IPM. Williantara \& Budiasih (2016) yang menganalisis pengaruh Pendapatan Asli Daerah (PAD), Dana Alokasi Umum (DAU), Dana Alokasi Khusus (DAK), dan Dana Bagi Hasil (DBH) terhadap Indeks Pembangunan Manusia (IPM). Harliyani \& Haryadi (2016) meneliti perkembangan pendapatan daerah dan belanja daerah dengan menganalisis kinerja keuangan daerah terhadap Indeks Pembangunan Manusia (IPM). Dari berbagai studi tersebut telah dilakukan analisis yang menghubungkan pendidikan dengan keuangan daerah, namun variabel yang diukur dengan indeks pendidikan masih jarang dilakukan, sehingga penelitian ini diharapkan dapat mengisi kesenjangan literatur yang ada.

Semakin berkurangnya disparitas atau ketidakmerataan suatu indikator antar wilayah dalam periode tertentu dapat tergambar oleh kondisi konvergensinya. Dua pendekatan utama pada studi konvergensi regional ini adalah sebagai berikut. Pertama, referensi klasik terkait dengan disparitas pembangunan regional adalah dari penelitiannya Williamson (1965) yang menggambarkan bagaimana proses konvergensi regional dan hubungannya dengan proses pembangunan nasional dan diprediksi bahwa disparitas pendapatan regional akan menurun (konvergen) setelah melewati tiga fase dari tingkat awal pembangunan hingga tahap kematangan (maturity). Ketidakmerataan regional tersebut dianalisis secara independen dari teori pertumbuhan. Kedua, konvergensi yang mulai dilakukan dengan menggunakan pendekatan lain oleh Barro et al., (1991) serta Barro \& Sala-i-Martin (1995, 1992) yang menggunakan pendekatan regresi cross-section pada tingkat pertumbuhan dengan tingkat awal pendapatan per kapita. Dalam hal ini, studi ini mengelaborasi kedua pendekatan tersebut untuk mendapatkan keunggulan dari setiap pendekatan serta menutup kelemahannya.

Penelitian mengenai konvergensi pembangunan regional yang dilakukan dalam dua dekade terakhir didominasi oleh pengamatan terhadap proses konvergensi pembangunan dari variabel ekonomi seperti: gross domestic bruto (GDP), income, ataupun pertumbuhannya, seperti studi tahun terkini yang dilakukan oleh Yaya et al. (2020), lalu pada satu dekade terakhir seperti yang dilakukan 
oleh Bouayad-Agha \& Lionel (2010), Firdaus \& Yusop (2009), hingga dua dekade terakhir oleh Choi \& Li (2000). Dari studi terkait konvergensi tersebut, banyak digunakan analisis statis maupun analisis dinamis untuk membuktikan hipotesis-hipotesisnya, sehingga dapat disimpulkan dari perkembangan studi terkait dengan konvergensi tersebut, secara umum terbagi pada dua pendekatan seperti yang disebutkan di atas, yaitu pendekatan pertama yang disebut dengan $\sigma$-convergence yang termasuk analisis statis dengan menghitung berbagai macam jenis koefisien variasi, dan pendekatan kedua yang disebut dengan $\beta$-convergence termasuk analisis dinamis yang didominasi oleh penggunaan model generalized method of moments (GMM).

Sedangkan, studi terkait dengan konvergensi pendidikan masih jarang dilakukan, khususnya yang mengamati konvergensi pendidikan di Indonesia. Lebih jauh dengan mengaitkannya dengan instrumen kebijakan keuangan daerah seperti dana transfer ke daerah seperti dalam studi ini. Studi yang menganalisis konvergensi telah dilakukan menggunakan berbagai macam pendekatan yang beragam, dan sepengetahuan penulis, studi yang menghubungkan konvergensi pendidikan dengan keuangan daerah masih terbatas, dengan pendekatan yang diadopsi dalam studi ini, terlebih lagi pada kasus Indonesia. Ada pula studi yang menganalisis interaksi variabel instrumen kebijakan keuangan daerah yang dihubungkan dengan pembangunan manusia, di mana indeks pendidikan merupakan salah satu bagian dari dimensinya, namun bukan menganalisis proses konvergensinya, seperti penelitian Wulandari et al. (2018) yang menganalisis pengaruh Pendapatan Asli Pemerintah Daerah, Dana Alokasi Umum, Dana Alokasi Khusus, Dana Saham, Legal Lainnya Pendapatan, Surplus/Defisit Anggaran terhadap Indeks Pembangunan Manusia (IPM) melalui Modal Pengeluaran di Indonesia dengan menggunakan path analysis. Kemudian Mutiha (2018) menguji pengaruh Pendapatan Asli Daerah, Dana Bagi Hasil Pajak, Dana Alokasi Umum dan Dana Alokasi Khusus untuk IPM yang digunakan sebagai patokan untuk menilai dan melihat kinerja pemerintah provinsi dalam hal memberikan layanan publik yang dianalisis menggunakan regresi berganda.

Dengan demikian, agar mengisi ketidakmerataan literatur terkait konvergensi pendidikan yang dikaitkan dengan keuangan daerah, serta agar dapat menjelaskan ketidakmerataan fenomena yang dijelaskan sebelumnya, maka studi ini bertujuan: pertama, untuk menganalisis konvergensi pendidikan antar wilayah di Indonesia. Kedua, untuk menelaah dampak kebijakan keuangan daerah terhadap konvergensi pendidikan tersebut. Sehingga diharapkan juga hasil dari studi ini dapat mengeritisi kebijakan penetapan dana transfer ke daerah dan belanja daerah yang saat ini berlaku dalam rangka mempercepat proses konvergensi pendidikan di Indonesia.

\section{METODE PENELITIAN}


Pemakaian data panel tahunan digunakan pada riset ini mulai dari tahun 2010 hingga dengan tahun 2019 untuk seluruh provinsi Indonesia, kecuali Provinsi Kalimantan Utara sebab keterbatasan data dari provinsi tersebut. Indikator pendidikan yang digunakan merupakan angka harapan lama sekolah, sebab angka melek huruf telah tidak bisa diaplikasikan lagi dalam menggambarkan pendidikan secara utuh serta mutu pendidikan, dan di sebagian besar wilayah angkanya sudah besar, hingga tidak dapat dibedakan untuk tingkatan pendidikan antardaerah dengan baik. Tidak hanya itu, digunakan data untuk mewakili variabel keuangan daerah yang bersumber dari Kementerian Keuangan- Republik Indonesia (Kemenkeu- RI), ialah dana alokasi umum (DAU), dana alokasi khusus (DAK), belanja langsung, dan belanja tidak langsung. Data keuangan daerah tersebut, ialah keseluruhan dana dari seluruh pemerintah daerah di suatu provinsi, baik pemerintah provinsi ataupun pemerintah kabupaten serta kota.

Secara ringkas, langkah-langkah penelitian dimulai dengan melakukan analisis dispersi dari ketidakmerataan pendidikan di Indonesia, di mana konvergensi terjadi ketika dispersi yang secara umum diukur oleh standard deviation (SD) dari suatu indikator antar daerah yang semakin menurun sepanjang waktu. Proses ini disebut dengan istilah $\sigma$-convergence Barro \& Sala-i-Martin (1995). Selain itu, dilengkapi dengan menggunakan ukuran weighted coefficient of variation yang merupakan modifikasi dari Indeks Williamson untuk mengukur inter-regional inequality seiring berjalannya waktu, dengan formula di bawah ini:

$$
C V w=\frac{\sqrt{\sum_{i=1}^{n}\left(Y_{i}-\bar{Y}\right)^{2} \frac{P_{i}}{P}}}{\bar{Y}}
$$

di mana: $C V_{w}=$ weighted coefficient of variation $; n=$ jumlah provinsi; $Y_{i}=$ indeks pendidikan dari provinsi $i ; \bar{Y}=$ rata-rata indeks pendidikan; $P_{i}=$ populasi dari provinsi $i$; and $P=$ jumlah populasi.

Meskipun indeks Williamson telah digunakan secara luas untuk menganalisis perubahan dalam ketimpangan regional dan karenanya konvergensi regional tidak dapat menunjukkan signifikansi konvergensi itu sendiri, maka lebih jauh dilakukan regresi dari nilai CVw terhadap tren waktu agar dapat diuji tingkat signifikansi dispersi yang terjadi seperti yang dilakukan Dekiawan (2014) sebagai berikut:

$$
Y_{t}=a_{1}+a_{2} T+e_{t}
$$

di mana, Y merupakan indikator dari variabel $\sigma$-convergence, yaitu $\mathrm{CVw}$; T mewakili tren waktu selang periode 2010-2019.

Selanjutnya, analisis kecepatan konvergensi diperkenalkan dalam analisis pertumbuhan dengan dikenal sebagai $\beta$-convergence yang dapat digunakan untuk menguji apakah daerah dengan tingkat indeks pendidikan yang relatif rendah tumbuh secara signifikan lebih cepat daripada daerah 
yang tingkat indeks pendidikannya relatif tinggi, sebagai indikasi tingkat ketimpangan yang menurun. Keunggulan penting dari $\beta$-convergence ini adalah analisis bersifat dinamis. Jika pengamatan jangka pendek tidak dapat menangkap dampak dari kebijakan publik, maka tidak dapat dilihat apakah dampak tersebut dalam kecenderungan jangka panjang.

Dalam studi empiris pada analisis $\beta$-convergence, analisis perilaku dan karakteristik wilayah dilakukan sebaga pengujian terhadap hipotesis konvergensi dilakukan, sehingga conditional $\beta$ convergence diterapkan untuk analisis dengan hipotesis terdapat perbedaan karakteristik dalam teknologi, preferensi, dan institusi antardaerah. Sedangkan dengan untuk hipotesis homogenitas karakteristik, lebih jauh bahwa pertumbuhan indeks pendidikan hanya dipengaruhi oleh tingkat indeks pendidikan awal saja, mendukung diterapkannya absolute $\beta$-convergence (Barro and Sala-iMartin 1995), sehingga penelitian ini akan menggunakan pendekatan yang pertama, yaitu menguji hipotesis dengan asumsi terdapat perbedaan karakteristik tersebut untuk antardaerahnya.

Metode analisis data panel dinamis digunakan untuk menestimasi model konvergensi, yaitu dengan model Generalized Method of Moments (GMM). Hal ini disebabkan oleh adanya lag variabel terikat, yaitu IP sebagai variabel bebas dalam spesifikasi modelnya. Masalah endogenitas muncul disebabkan oleh adanya hubungan dinamis, sehingga akan menghasilkan penduga yang bias dan tidak konsisten jika model diolah dengan analisis data panel statis (Verbeek 2004).

Fakta berkembangnya hubungan yang bersifat dinamis antara variabel-variabel ekonomi dalam hubungannya dengan analisis dinamika penyesuaian mengakibatkan banyaknya penggunaan analisis data panel dinamis. Keberadaan lag variabel terikat sebagai variabel bebas yang mengakibatkan munculnya masalah endogenitas merupakan ciri dari hubungan dinamis, oleh karena akan menghasilkan penduga yang bias dan tidak konsisten jika model diestimasi dengan analisis data panel statis, sehingga dapat diatasi dengan model GMM. Dengan demikian, model pada penelitian ini diestimasi menggunakan metode data panel dinamis dengan model GMM mengikuti (Arellano and Bond 1991) dengan model first differences (FD-GMM) terlebih dahulu, kemudian karena GMM estimator in first differences telah dikritik dalam literatur, maka diestimasi model the system (SysGMM) seperti yang disarankan oleh Blundell \& Bond (1998), di mana suatu sistem persamaan diestimasi dalam first differences. Maka, evaluasi model data panel dinamis dilaksanakan dalam menentukan model yang tepat sehingga memenuhi kriteria tidak bias, konsisten, dan valid.

Pengujian empiris terhadap prediksi konvergensi dari teori pertumbuhan neoklasik dengan asumsinya tentang diminishing returns to capital, dilakukan dengan regresi model dari Barro \& Salai-Martin (1995). Model ini mengaplikasikan persamaan yang menghubungkan tingkat pertumbuhan indeks pendidikan antara dua titik waktu pada level awal indeks pendidikan. Pengujian hipotesis conditional $\beta$-convergence digunakan model berikut: 


$$
Y_{i, t}=\frac{1}{T} \ln \left(\frac{Y_{i, t}}{Y_{i, t-1}}\right)=\frac{1}{T}\left[\left(\ln \left(Y_{i, t}\right)-\ln \left(Y_{i, t-1}\right)\right]\right.
$$

$Y_{i, t}$ pada persamaan 3 selanjutnya digunakan sebagai variabel terikat pada persamaan 4 sebagai berikut:

$$
\begin{aligned}
& Y_{i, t}=\alpha-\beta \ln Y_{i, t-1}+\gamma X_{i, t-1}+u_{i, t-1} \\
& -\beta=\left(1-e^{-\lambda}\right) \quad \text { atau } \quad e^{-\lambda}=1+\beta
\end{aligned}
$$

di mana: $Y=$ variabel pertumbuhan; $X=$ variabel penjelas penentu steady state $T=$ jumlah periode waktu pengamatan; $t=$ tahun; $i=$ provinsi; $e=$ bilangan logaritma natural; $u=$ error term.

Sedangkan untuk mengetahui dampak keuangan daerah terhadap indeks pendidikan digunakan model conditional $\beta$-convergence yang merupakan model absolute $\beta$-convergence ditambah dengan variabel penjelas yang menjelaskan karakteristik masing-masing provinsi, dalam hal ini digunakan variabel-variabel dari instrumen kebijakan keuangan daerah, yaitu DAU, DAK, belanja langsung, dan belanja tidak langsung. Untuk melakukan tes terhadap hipotesis conditional $\beta$ convergence akan menggunakan spesifikasi model pada persamaan 6 sebagai berikut:

$$
\begin{gathered}
\ln \left(I P_{i, t}\right)-\ln \left(I P_{i, t-1}\right)=\beta_{0}+\beta_{1} \ln \left(I P_{i, t-1}\right)+\beta_{2} \ln \left(D A U_{i, t}\right)+\beta_{3} \ln \left(D A K_{i, t}\right)+ \\
\beta_{4} \ln \left(B L_{i, t}\right)+\beta_{5} \ln \left(B T L_{i, t}\right)+u_{i, t}
\end{gathered}
$$

di mana: $I P=$ indeks pendidikan; $D A U=$ dana alokasi umum; $D A K=$ dana alokasi khusus; $B L=$ belanja langsung; $B T L=$ belanja tidak langsung $t=$ tahun; $i=$ provinsi; $u=$ error term .

Proses konvergensi dapat dilihat jika koefisien dari $\beta_{1}$ bernilai kurang dari 1 , dengan kecepatan konvergensi ditulis sebagai $\lambda$ berdasarkan Barro \& Sala-i-Martin (1995) pada persamaan 7, di mana kecepatan konvergensi tersebut dapat mengestimasi kecepatan indeks pendidikan sampai pada konvergensi dan menuju tingkat kemapanan atau steady state, serta uji half-life pada persamaan $\mathbf{8}$ menunjukkan waktu yang dibutuhkan untuk mencapai kondisi steady state dari proses konvergensi indeks pendidikan atau waktu yang diperlukan untuk tercapainya setengah dari konvergensi indeks pendidikan dinyatakan dengan $\tau$.

$$
\begin{aligned}
& \lambda=-\frac{\ln \left(\beta_{1}\right)}{T} \\
& \tau=\frac{-\ln (0.5)}{-\ln \left(\beta_{1}\right) / T}=\frac{\ln (2)}{\lambda}
\end{aligned}
$$

di mana: $\lambda=$ kecepatan konvergensi dari indeks pendidikan; $\beta_{1}=$ koefisien lag indeks pendidikan; $T=$ jumlah periode waktu pengamatan; $\tau=$ half-life of convergence .

\section{HASIL DAN PEMBAHASAN}

Untuk menglarifikasi terjadinya konvergensi atau penurunan dispersi pada kesenjangan pendidikan di Indonesia ini, maka lebih jauh dilakukan analisis regresi nilai koefisien variasi terhadap 
tren waktu dalam pengujian tingkat signifikansi penurunan dari nilai koefisien variasi tersebut. Hasil estimasi OLS dapat dilihat dalam Gambar 2 di bawah menggambarkan bahwa value koefisien tren waktu pada indeks pendidikan di Indonesia dengan indikator koefisien variasi mengalami konvergensi dan signifikan pada taraf $1 \%$ selama periode pengamatan studi. Hal ini dilihat nilai koefisien yang negatif pada variabel tren waktu terhadap Indeks Pendidikan (IP). Namun kondisi kesenjangan masih tergolong tinggi sampai dengan tahun terakhir, yaitu lebih dari 0,7 atau sebesar 0,777 pada tahun 2019 .

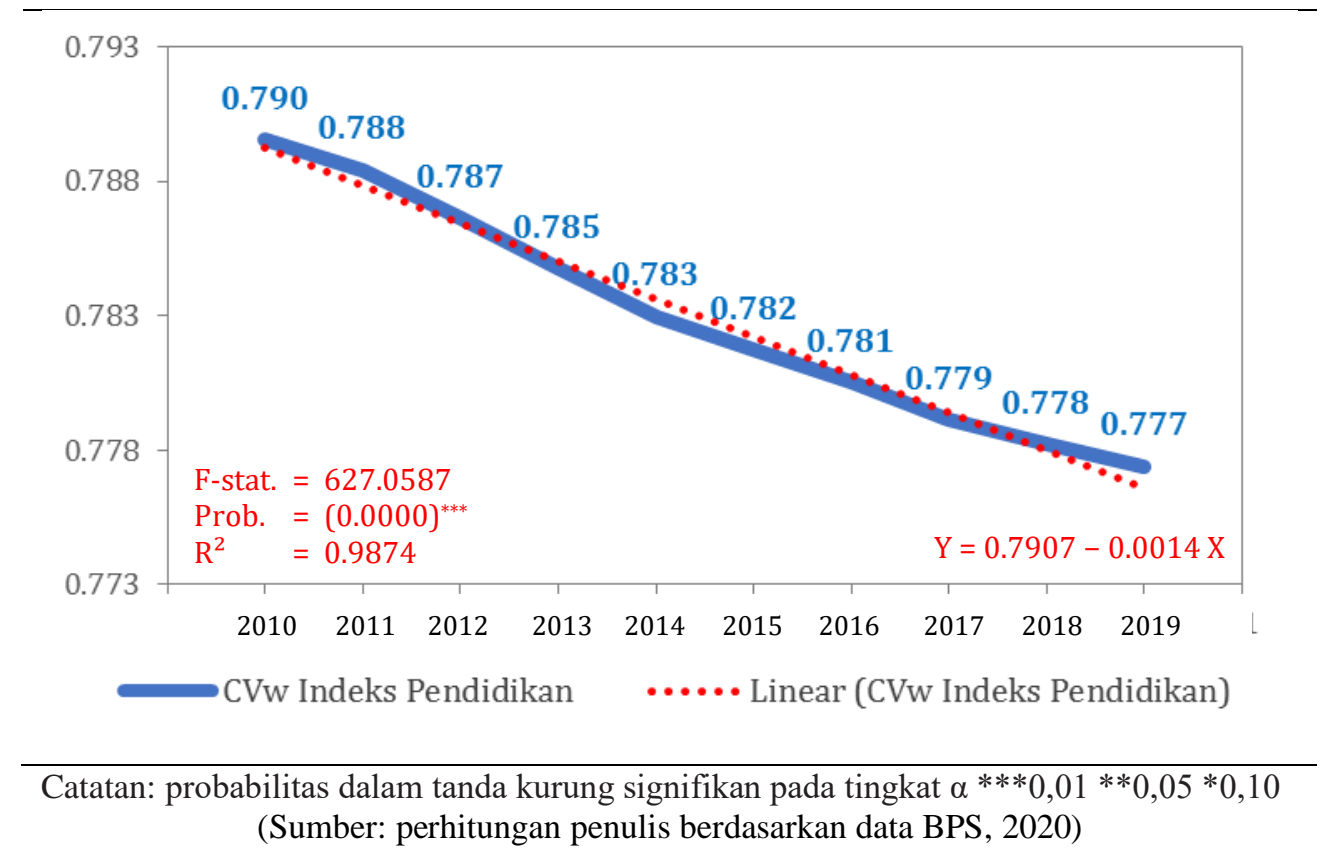

Gambar 2. Tren Dispersi dari Kesenjangan Indeks Pendidikan di Indonesia, 2010-2019 $(\sigma$-Convergence)

Selanjutnya, dilakukan analisis dengan mengestimasi model conditional $\beta$-convergence. Hasilnya dapat dilihat dalam Tabel 1 ditemukan bahwa penduga koefisien dari lag variabel terikat yang sebesar 0,8402735 lebih besar dibandingkan dengan penduga dengan model FE sebesar 0,8338194, nilai ini lebih kecil dibandingkan dengan model OLS pada nilai 0,9614603. Hal ini mengindikasikan bahwa penduga pada model FD-GMM tidak memiliki sifat bias. Uji Arellano-Bond dengan model FD-GMM memerlihatkan uji signifikansi AR(1) secara signifikan dengan statistik uji sebesar -4,2007, serta uji signifikansi $A R(2)$ menunjukkan hasil yang tidak signifikan dengan statistik uji sebesar-1,2541, oleh karena itu dapat disimpulkan penduga dengan model FD-GMM ini memiliki sifat konsisten. Hasil uji Sargan tidak signifikan dengan statistik uji bernilai 31,93876 menunjukkan penduga dengan model FD-GMM menggunakan instrumen yang bersifat valid. Meskipun nilai penduga dengan model FD-GMM bersifat konsisten dan menggunakan instrumen yang bersifat valid, dan hasil pengujian continuum menyatakan jika penduga tersebut tidak bersifat 
Prosiding The 1st National Conference on Applied Business, Education, \& Technology (NCABET)"

Unversitas Bina Bangsa 2021

DOI Article : 10.46306/ncabet.v1i1.21

bias, maka model dengan model FD-GMM mungkin sesuai digunakan dalam analisis conditional $\beta$ convergence ini.

Tabel 1. Hasil Estimasi Model $\beta$-Convergence

\begin{tabular}{|c|c|c|c|c|}
\hline Parameter & $\begin{array}{l}\text { Ordinary Least } \\
\text { Squares }\end{array}$ & $\begin{array}{l}\text { Fixed } \\
\text { Effect }\end{array}$ & $\begin{array}{l}\text { First- } \\
\text { Differences } \\
\text { GMM }\end{array}$ & $\begin{array}{c}\text { System } \\
\text { GMM }\end{array}$ \\
\hline \multirow[t]{2}{*}{$\ln \_I P_{i, t-1}$} & .9614603 & .8338194 & .8402735 & .8996416 \\
\hline & $(0.000)^{* * * *}$ & $(0.000)^{* * * *}$ & $(0.000)^{* * *}$ & $(0.000)^{* * * *}$ \\
\hline \multirow[t]{2}{*}{ In_DAK } & -.000343 & -.000312 & -.000861 & -.001323 \\
\hline & $(0.165)$ & $(0.493)$ & $(0.000)^{* * * *}$ & $(0.000)^{* * * *}$ \\
\hline \multirow[t]{2}{*}{ In_DAU } & .0000322 & .0002406 & -.000756 & -.001459 \\
\hline & $(0.879)$ & $(0.693)$ & $(0.000)^{* * *}$ & $(0.000)^{* * *}$ \\
\hline \multirow[t]{2}{*}{ In_BTL } & .0034141 & .0201687 & .0115388 & .0003098 \\
\hline & $(0.160)$ & $(0.000)^{* * * *}$ & $(0.892)$ & $(0.817)$ \\
\hline \multirow[t]{2}{*}{ ln_BL } & -.002686 & -.000818 & .0084339 & .0090025 \\
\hline & $(0.101)^{*}$ & $(0.772)$ & $(0.000)^{* * * *}$ & $(0.000)^{* * *}$ \\
\hline \multirow[t]{2}{*}{ _cons } & .1652204 & .4121397 & .3990779 & .3281051 \\
\hline & $(0.000)^{* * *}$ & $(0.000)^{* * * *}$ & $(0.000)^{* * *}$ & $(0.000)^{* * * *}$ \\
\hline Implied $\lambda$ & 3.93 & 18.17 & 17.40 & 10.58 \\
\hline Half-life & 17.64 & 3.81 & 3.98 & 6.55 \\
\hline \multirow{2}{*}{\multicolumn{5}{|c|}{$\begin{array}{l}\text { Arellano-Bond test } \\
\text { for } A R(1)\end{array}$}} \\
\hline & & & -4.2007 & -4.3626 \\
\hline & & & $(0.000)^{* * * *}$ & $(0.000)^{* * *}$ \\
\hline \multirow[t]{2}{*}{ for $A R(2)$} & & & -1.2541 & -1.5132 \\
\hline & & & $(0.2098)$ & $(0.1302)$ \\
\hline \multirow[t]{2}{*}{ Sargan test } & & & 31.93876 & 28.91468 \\
\hline & & & $(0.6167)$ & $(0.9507)$ \\
\hline
\end{tabular}

Catatan: probabilitas dalam tanda kurung signifikan pada tingkat $\alpha * * * 0,01 * * 0,05 * 0,10$

(Sumber: perhitungan penulis berdasarkan data BPS dan Kemenkeu-RI, 2020)

Kemudian perlu dilakukan estimasi pula dengan menggunakan model Sys-GMM. Model SysGMM memiliki penduga koefisien dari lag variabel terikat sebesar 0,8996416, nilai tersebut lebih besar dari penduga model FE namun lebih kecil dari penduga model OLS, oleh karen itu syarat continuum terpenuhi, maka penduga tidak bersifat bias. Uji Arellano-Bond menunjukkan bahwa statistik uji hasil uji signifikansi AR(1) adalah signifikan sebesar -4,3626, serta statistik uji hasil uji signifikansi AR(2) adalah tidak signifikan sebesar-1,5132 yang. Hal ini berati penduga model SysGMM ini bersifat konsisten. Didapatkan hasil uji Sargan adalah tidak signifikan dengan statistik uji sebesar 28,91468 menyatakan bahwa penduga dengan pendekatan Sys-GMM bersifat valid. Kesimpulan dari ketiga hasil pengujian tersebut adalah model Sys-GMM memenuhi seluruh kriteria model panel dinamis yang tepat, sehingga analisis dengan pendekatan conditional $\beta$-convergence dapat diambil kesimpulannya. Dengan demikian diambil keputusan untuk menggunakan model SysGMM karena penduga koefisien dari lag variabel terikat lebih berada di tengah-tengah antara penduga dari model FE dan OLS, dibandingkan dengan model FD-GMM. 
Model konvergensi di atas dapat menginformasikan tentang beberapa faktor yang memengaruhi konvergensi indeks pendidikan di Indonesia. Intervensi terhadap faktor-faktor ini perlu dilakukan agar dapat mempercepat terjadinya proses konvergensi. Intervensi dapat dilakukan dengan lebih fokus terhadap daerah yang memiliki tingkat indeks pendidikan yang lebih rendah agar pembangunan pendidikannya dapat mengalami akselerasi yang lebih cepat sehingga proses konvergensi pun lebih cepat terjadi. Koefisien variabel lag IP dengan nilai lebih kecil dari satu menggambarkan proses konvergensi terjadi berhubungan dengan ketidakmerataan IP, hal ini mengindikasikan bahwa dampak dana transfer ke daerah secara agregat dapat memberikan kontribusi bagi kecepatan konvergensi IP sebesar 10,58\% dalam satu dekade atau 1,058\% per tahun dengan half-life of convergence atau diperlukan waktu sekitar 6,55 dekade atau 65,5 tahun lamanya untuk menutup setengah ketidakmerataannya.

Model estimasi Sys-GMM pada analisis dengan pendekatan conditional $\beta$-convergence ini merupakan model agregat terbaik yang dapat menjelaskan dampak dana transfer ke daerah terhadap konvergensi pendidikan di Indonesia. Instrumen-instrumen dari dana transfer ke daerah dalam studi ini dijelaskan secara parsial untuk masing-masing variabel yang terdiri dari variabel Dana Alokasi Khusus (DAK) dan Dana Alokasi Umum (DAU), serta variabel dari belanja daerah yang terdiri dari belanja langsung dan belanja tidak langsung.

Model tersebut memberikan hasil koefisien dari regresi variabel DAK pada model agregat sebesar $-0,001323$. Hal ini mengindikasikan bahwa variabel ini berpengaruh negatif secara signifikan terhadap akselerasi proses konvergensi pendidikan di Indonesia. Setiap peningkatan 1\% DAK akan menurunkan kecepatan konvergensi dari IP sebesar -0,001323\% (ceteris paribus). Begitu pun dengan variabel DAU pada model agregat sebesar -0 , 001459. Hal ini mengindikasikan bahwa variabel ini berpengaruh negatif secara signifikan terhadap akselerasi proses konvergensi pendidikan di Indonesia. Setiap peningkatan 1\% DAU akan menurunkan kecepatan konvergensi dari IP sebesar $-0,001459 \%$ (ceteris paribus).

Meskipun penurunan angka kecepatan konvergensi di atas cukup kecil, namun dampak negatif ini tetap perlu diperhatikan. Kondisi ini wajar terjadi karena besaran DAK dan DAU yang diatur untuk diberikan kepada daerah sesuai dengan formula yang tergantung dari kondisi dari daerah tersebut. Ini mengindikasikan bahwa kondisi dari daerah dengan tingkat IP lebih tinggi memiliki kuantitas penerimaan yang relatif lebih besar dari pada daerah dengan tingkat IP yang lebih rendah. Kami berpendapat bahwa kondisi ini diindikasikan karena komponen IP yang dijadikan formulasi dalam menilai kebutuhan daerah untuk menentukan besaran transfer ke daerah belum menjadi prioritas utama, padahal IP ini adalah salah satu tujuan dari sisi pembangunan regional. 
Variabel Belanja Tidak Langsung pada model agregat memiliki koefisien sebesar 0,0003098 yang mengindikasikan bahwa variabel ini berpengaruh positif terhadap peningkatan akselerasi proses konvergensi pendidikan di Indonesia namun tidak signifikan. Peningkatan $1 \%$ Belanja Tidak Langsung hanya akan meningkatkan akselerasi proses konvergensi pendidikan sebesar 0,0003098\% (ceteris paribus). Hal ini dinilai cukup wajar karena belanja yang dianggarkan tidak terkait secara langsung dengan pelaksanaan program dan kegiatan pembangunan. Namun meskipun peningkatan angkanya cukup kecil (tidak signifikan), dampak positif ini tetap perlu diperhatikan, sehingga harapannya kondisi ini dapat berubah menjadi lebih akseleratif.

Koefisien regresi Variabel Belanja Langsung adalah sebesar 0,0090025. yang berarti variabel ini berpengaruh positif secara signifikan terhadap peningkatan akselerasi proses konvergensi pendidikan di Indonesia. Peningkatan 1\% Belanja Langsung akan berdampak pada peningkatan akselerasi proses konvergensi pendidikan sebesar 0,0090025\% (ceteris paribus). Hasil ini sudah sesuai dengan tujuan belanja langsung untuk pembangunan regional melalui program-program yang terkait dengan pendidikan di masing-masing daerah.

Hasil dari penelitian ini konsisten dengan Wulandari et al. (2018) dengan menggunakan path analysis yang menunjukkan bahwa Pendapatan Asli Pemerintah Daerah (PAD), Dana Alokasi Umum (DAU), Dana Alokasi Khusus (DAK), Dana Bagi Hasil (DBH), secara langsung memengaruhi Indeks Pendidikan, meskipun tidak dianalisis proses konvergensinya. Hasil penelitian ini pun sejalan dengan temuan Mutiha (2018) yang menggunakan pendekatan maupun model yang berbeda, ditunjukkan bahwa Pendapatan Asli Daerah (PAD) memiliki dampak positif secara signifikan terhadap Indeks Pendidikan, sementara Dana Bagi Hasil Pajak, Dana Alokasi Umum dan Dana Alokasi Khusus juga memiliki dampak negatif yang signifikan terhadap Indeks Pendidikan. Mereka tidak menganalisis proses konvergensinya, namun dikatakan bahwa dampak negatif yang terjadi dimungkinkan karena pada tingkat tertentu, Dana Perimbangan tidak digunakan untuk membiayai pengeluaran langsung. Sebagaimana didukung oleh teori tersebut, bahwa pengeluaran langsung berdampak langsung terhadap pemeliharaan layanan publik, dimana pada akhirnya berdampak pada peningkatan kualitas pendidikan. Dengan demikian, sangat menarik untuk memantik analisis untuk studi lebih lanjut dalam menyeimbangkan pembahasan dari sisi anggaran penerimaan dan belanja pemerintah.

Kemudian kami berpendapat bahwa beberapa provinsi yang memiliki DAU dan DBH yang relatif lebih kecil dapat mempertahankan tingkat pertumbuhan di atas rata-rata seluruh provinsi, atau dikatakan relatif lebih cepat. Hal ini diindikasikan karena kinerja dari kebijakan dana perimbangan lain yang memberikan kontribusi positif pada proses konvergensi, antara lain instrumen DAK dan DD masih dominan, namun agar lebih baik lagi, maka seharusnya kinerja semua instrumen dana 
perimbangan tersebut lebih bersinergi lagi, sehingga dapat memberikan efek yang lebih cepat terhadap proses konvergensi pendidikan di Indonesia. Selanjutnya dapat dikatakan bahwa instrumen kebijakan fiskal ini relatif lebih efektif dalam mengakselerasi konvergensi pembangunan, sebagaimana Firdaus \& Yusop (2009) yang menemukan bahwa konvergensi regional yang dikur dengan income per capita dengan variabel penjelas investasi dan tenaga kerja hanya memiliki kecepatan konvergensi kecepatan $0.29 \%$ per tahunnya dan dikatakan sangat lambat, sehingga kondisi ini akan lebih sulit untuk diintervensi lebih lanjut dibandingkan dengan instrumen kebijakan fiskal yang pada prinsipnya dapat diintervensi oleh pemerintah secara langsung.

\section{KESIMPULAN DAN SARAN}

Berdasarkan hasil analisis statis dengan pendekatan $\sigma$-convergence yang ditunjukkan oleh ukuran koefisien variasi menggunakan penghitungan Indeks Williamson yang dimodifikasi, hasilnya ditemukan kesenjangan indeks pendidikan di Indonesia selama periode 2010-2019, namun sedang telah terjadi dispersi dalam kesenjangannya tersebut, artinya konvergensi pendidikan berlaku. Hal ini dikonfirmasi oleh hasil analisis tren yang sesuai dengan hipotesis dari teori neoklasik di mana telah ditunjukkan bahwa seluruh provinsi dengan tingkat indeks pendidikan yang lebih tinggi tumbuh relatif lebih lambat, dan sebaliknya, provinsi dengan tingkat indeks pendidikan yang lebih rendah dominan tumbuh relatif lebih cepat, sehingga terlihat proses dalam mengejar ketertinggalannya.

Selanjutnya, analisis dinamis dengan pendekatan conditional $\beta$-convergence dengan model Sys-GMM menemukan model yang dibangun dengan variabel penjelas dari kebijakan keuangan daerah dapat menyebabkan proses konvergensi pendidikan. Kecepatan dari konvergensinya adalah sebesar 1,058\% per tahun, oleh karena itu butuh sekitar 65,5 tahun lamanya waktu yang dibutuhkan untuk menutup setengah kesenjangannya (half-life of convergence). Berdasarkan tinjauan literatur, kondisi tersebut dapat dikatakan cukup lambat. Ini merupakan konsekuensi secara agregat dari Dana Alokasi Khusus (DAK) dan Dana Alokasi Umum (DAU) yang tandanya negatif menyebabkan pelambatan pada proses konvergensi, serta Belanja Tidak Langsung dan Belanja Langsung yang telah memberikan kontribusi positif bagi proses konvergensi.

Kedua pendekatan analisis statis maupun dinamis ini adalah identik dan konvergensi pendidikan telah terverifikasi, meskipun dapat dikatakan relatif lambat. Bukti ini membuka peluang bagi pengkajian kembali pada justifikasi komponen pembobotan dalam menentukan besarnya jumlah dana transfer ke daerah guna percepatan proses konvergensi pendidikan di Indonesia. Solusi yang penulis dapat berikan untuk dapat mengatasi hal ini adalah dengan memberikan kriteria khusus pada daerah yang tingkat indeks pendidikannya lebih rendah, serta menguraikan masing-masing dimensi dari indeks pembangunan manusia pada formulasi penentuan dana transfer ke daerah, sehingga dapat 
memberikan prioritas lebih pada bobot dimensi indeks pendidikan maupun dimensi lainnya, seperti indeks kesehatan dan indeks daya beli masyarakat. Pengakselerasian konvergensi memerlukan intervensi terhadap faktor-faktor tersebut perlu sehingga intervensi akan lebih fokus pada daerah dengan tingkat indeks pendidikan yang lebih rendah supaya peningkatan pertumbuhannya berjalan lebih cepat dan diharapkan dapat mengejar kesenjangannya, sehingga proses konvergensi pendidikan dapat lebih cepat terjadi.

\section{DAFTAR PUSTAKA}

Arellano, Manuel, and Stephen Bond. 1991. "Some Tests of Specification for Panel Data: Monte Carlo Evidence and an Application to Employment Equations." Review of Economic Studies 58: 277-97.

Barro, Robert J., and Xavier Sala-i-Martin. 1995. Economic Growth. New York: McGraw-Hill Inc.

Barro, Robert J., Xavier Sala-I-Martin, Olivier Jean Blanchard, and Robert E. Hall. 1991. "Convergence Across States and Regions." Brookings Papers on Economic Activity 1991 (1): 107. https://doi.org/10.2307/2534639.

Barro, Robert J., and Xavier X. Sala-i-Martin. 1992. "Convergence Xavier Sala-i-Martin.” Journal of Political Economy 100 (2): 223-51. https://doi.org/10.1086/261816.

Blundell, Richard, and Stephen Bond. 1998. "Initial Conditions and Moment Restrictions in Dynamic Panel Data Models.” Journal of Econometrics. https://doi.org/10.1016/S0304-4076(98)000098.

Bouayad-Agha, Salima, and Védrine Lionel. 2010. "Estimation Strategies for a Spatial Dynamic Panel Using Gmm. a New Approach to the Convergence Issue of European Regions." Spatial Economic Analysis 5 (2): 205-27. https://doi.org/10.1080/17421771003730711.

Choi, Hak, and Hongyi Li. 2000. "Economic Development and Growth Convergence in China." Journal of International Trade and Economic Development. https://doi.org/10.1080/096381900362535.

Dekiawan, Hermada. 2014. "Konvergensi Penerimaan Dan Pengeluaran Pemerintah Provinsi Di Indonesia: Pendekatan Data Panel Dinamis Spasial.” Buletin Ekonomi Moneter Dan Perbankan 17 (1): 99-128. https://doi.org/10.21098/bemp.v17i1.52.

Firdaus, Muhammad, and Zulkornain Yusop. 2009. "Dynamic Analysis of Regional Convergence in Indonesia.” International Journal of Economics and Management 3 (1): 73-86.

Hakim, Aziz Rachman, Analis Keuangan, Gedung Radius Prawiro, and Jalan Wahidin No. 2020. “Jurnal De Is Edisi 6, Volume VI, Januari-April 2020” VI (6): 99-108.

Harliyani, Eka Marisca, and Haryadi Haryadi. 2016. "Pengaruh Kinerja Keuangan Pemerintah Daerah Terhadap Indeks Pembangunan Manusia Di Provinsi Jambi." Jurnal Perspektif Pembiayaan Dan Pembangunan Daerah 3 (3 SE-): 129-40. https://onlinejournal.unja.ac.id/JES/article/view/3514.

Kurniawati, Lestari, Dian Handayani, and Eko Nur Surachman. 2018. "Kerangka Konseptual Pengadaan Infrastruktur Pendidikan Dasar Dan Menengah Melalui KPBU Dengan Skema Belanja Ketersediaan Layanan.” Jurnal Defis IV (4): 56-71.

Mutiha, A H. 2018. "The Effect of Regional Own-Source Revenue, Tax Revenue-Sharing Fund, 
General Allocation Fund and Special Allocation Fund to the Human Development Index (Based on the Study of Provincial Government in Indonesia)." KnE Social Sciences 3 (11): 609. https://doi.org/10.18502/kss.v3i11.2792.

Rifa'i, Achmad, and Listiono. 2018. “Analisis Dampak Kebijakan Desentralisasi Fiskal Terhadap Penyediaan Fasilitas Pendidikan: Pendekatan Model Difference in Difference." Jurnal Defis IV (4): 72-80.

Sembiring, Erika Apulina. 2019. "Pengaruh Pendapatan Asli Daerah, Dana Alokasi Umum, Dan Dana Alokasi Khusus Terhadap Indeks Pembangunan Manusia Di Kabupaten Dan Kota Provinsi Sumatera Utara." Accumulated Jornal 1 (2): 160-70.

Sumardjoko, Imam. 2017. “Analisis Efisiensi Belanja Langsung Melalui Penguatan Belanja Modal Daerah Dan Implikasinya Terhadap Pertumbuhan Ekonomi Regional.” Jurnal Defis I (1): 7190.

Triyanto, and Catur Panggih Pamungkas. 2017. "Implikasi Pengalihan Kewenangan Pendidikan Menengah Terhadap Beban Fiskal Dan Kebijakan Alokasi DAU.” Jurnal Defis I (1): 23-32.

Verbeek, M. 2004. Modern Econometrics. USA: John Wiley and Sons Inc.

Williamson, J.G. 1965. "Regional Inequality and the Process of National Development: A Description of the Patterns." Economic Development and Cultural Change 13 (4): 3-45.

Williantara, Gede, and I Budiasih. 2016. "Pengaruh Pendapatan Asli Daerah, Dana Alokasi Umum, Dana Alokasi Khusus, Dan Dana Bagi Hasil Pada Indeks Pembangunan Manusia.” E-Jurnal Akuntansi 16 (3): 2044-70.

Wulandari, Eva, Muhamad Wahyudi, and Utpala Rani. 2018. "Effect of Original Local Government Revenues, General Allocation Funds, Special Allocation Funds, Share Funds, Other Legal Revenues, Budget Surplus/Deficit to Human Development Index Through Capital Expenditures: Case Study of Regencies/Municipalities In ." Review of Integrative Business and Economics Research 7 (2): 125-37. https://doi.org/ISSN: 2304-1013.

Yaya, Ola Oluwa S., Fumitaka Furuoka, Kiew Ling Pui, Ray Ikechukwu Jacob, and Chinyere M. Ezeoke. 2020. "Investigating Asian Regional Income Convergence Using Fourier Unit Root Test with Break." International Economics 161: 120-29. https://doi.org/10.1016/j.inteco.2019.11.008. 